\title{
Increased Plasma Exposures of Conjugated Metabolites of Morinidazole in Renal Failure Patients: A Critical Role of Uremic Toxins ${ }^{\mathbb{S}}$
}

\author{
Fandi Kong, Xiaoyan Pang, Kan Zhong, Zitao Guo, Xiuli Li, Dafang Zhong, and Xiaoyan Chen \\ Shanghai Institute of Materia Medica, Chinese Academy of Sciences, Shanghai (F.K., X.P., K.Z., Z.G., X.L., D.Z., X.C.), and \\ University of Chinese Academy of Sciences, Beijing (F.K., D.Z., X.C.), People's Republic of China
}

Received December 1, 2016; accepted March 15, 2017

\begin{abstract}
Morinidazole is a 5-nitroimidazole drug. Its sulfate conjugate M7 was a sensitive substrate of organic anion transporter 1 (OAT1) and OAT3, whereas $\mathbf{N}^{+}$-glucuronides M8-1 and M8-2 were only OAT3 substrates. In chronic renal failure (CRF) patients, plasma exposures of the three conjugates increased by 15 -fold, which were also found in $5 / 6$ nephrectomized $(5 / 6 \mathrm{Nx})$ rats in this study. Although the transcriptions of Oat 1 and Oat 3 in 5/6 Nx rat kidneys decreased by $50 \%$, no difference was observed on the three conjugate uptakes between control and 5/6 Nx rat kidney slices. Thus, the highly elevated endogenous uremic toxins in 5/6 Nx rats and humans, namely, 3-carboxy-4-methyl-5propyl-2-furanpropionate (CMPF), hippuric acid (HA), and indoxyl sulfate (IS), were considered as influential factors. In rat kidney slices,
\end{abstract}

\section{Introduction}

Chronic kidney diseases are major chronic illnesses primarily threatening public health, as reported by the World Health Organization in 2012 (Moll et al., 2014). The absorption, distribution, metabolism, and extraction processes of drugs differ in patients with chronic renal failure (CRF), and dose adjustment should be considered in clinical uses (Verbeeck and Musuamba, 2009). CRF can reduce the renal clearance of drugs by decreasing the glomerular filtration rate (Naud et al., 2011). For example, the pharmacokinetic characteristic of memantine changed with varying glomerular filtration rate in CRF patients, and the dose was reduced in half for severe renal impairment patients (Periclou et al., 2006).

Renal dysfunction can also affect the expression and function of kidney transporters (Verbeeck and Musuamba, 2009; Naud et al., 2011; Schwenk and Pai, 2016). Sakurai et al., (2004) showed that human organic anion transporter 1 (OAT1) and OAT3 mRNA levels in the kidneys of patients with renal diseases were lower than those in normal kidneys; they demonstrated that the elimination constant of cefazolin, a substrate of OAT3, was significantly correlated with OAT3 mRNA levels in humans.

This work was financially supported by Youth Innovation Promotion Association CAS.

https://doi.org/10.1124/dmd.116.074492.

S This article has supplemental material available at dmd.aspetjournals.org. the uptake of M7, M8-1, and M8-2 was dose dependently reduced by HA and IS, whose plasma concentrations were elevated 5 times in 5/6 Nx rats. In OAT3-overexpressed cells, the three conjugate uptakes were inhibited by CMPF, HA, and IS with $\mathrm{IC}_{50}$ values of $19.2,87.4$, and $222 \mu \mathrm{M}$ (M7); 8.53, 39.4, and $161 \mu \mathrm{M}$ (M8-1); and 6.75, 24.1, and 78.3 $\mu \mathrm{M}$ (M8-2), respectively. In OAT1-overexpressed cells, CMPF, HA, and IS showed weak inhibition on M7 uptake with $\mathrm{IC}_{50}$ values of 187,162 , and $200 \mu \mathrm{M}$, correspondingly. Results suggest that the reduced mRNA expression of renal transporters in CRF patients may not influence the activities of these transporters. However, accumulated uremic toxins may inhibit the transporters, particularly OAT3, leading to plasma exposure changes of relevant substrates.

ABBREVIATIONS: AUC, area under the plasma concentration-time curve; $\mathrm{AUC}_{0-\infty}$, area under the concentration-time curve from 0 hours to the infinite time; BUN, blood urea nitrogen; CMPF, 3-carboxy-4-methyl-5-propyl-2-furanpropionate; CRF, chronic renal failure; HA, hippuric acid; HBSS, Hanks' balanced salt solution; HEK293, human embryonic kidney 293; IAA, indole-3-acetic acid; IS, indoxyl sulfate; $K_{m}$, Michaelis-Menten constant; LC-MS/MS, liquid chromatography with tandem mass spectrometry; OAT, organic anion transporter; PCR, polymerase chain reaction; SD rats, Sprague-Dawley rats; $5 / 6 \mathrm{Nx}$ rat, $5 / 6$ nephrectomized rat; $V_{\max }$, maximum uptake rate. 


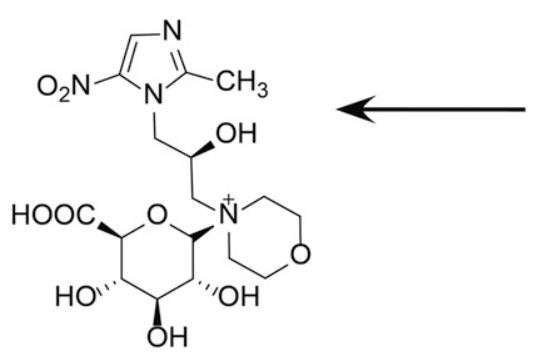

M8-1

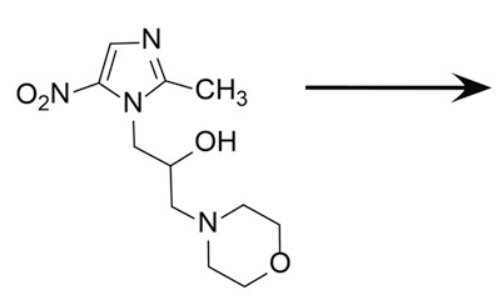

Morinidazole, $\mathrm{MO}$<smiles>Cc1ncc([N+](=O)[O-])n1CC(CN1CCOCC1)OS(=O)(=O)O</smiles>

M7<smiles>Cc1ncc([N+](=O)[O-])n1C[C@H](O)CN1CCOCC1[C@H]1O[C@H](C(=O)O)[C@@H](O)[C@H](O)[C@H]1O</smiles>

M8-2

Fig. 1. Major metabolic pathways of morinidazole in humans.

humans, morinidazole was primarily metabolized via $N^{+}$-glucuronidation forming the $N^{+}$-glucuronide of $S$-morinidazole M8-1 and $N^{+}$-glucuronide of $R$-morinidazole M8-2, as well as $O$-sulfation forming the sulfate conjugate M7 (Fig. 1) (Gao et al., 2012).

Morinidazole and its conjugates M7, M8-1, and M8-2 were mainly excreted through urine, accounting for $21.2 \%, 13.0 \%, 6.6 \%$, and $28.4 \%$ of the dose (Zhong et al., 2014). The $\mathrm{AUC}_{0-t}$ values (area under the concentration-time curve from 0 hours to the last sampling time) of conjugates M7, M8-1, and M8-2 in severe renal impairment patients were 15.1-, 20.4-, and 17.4-fold higher than those in healthy subjects with the same dose, whereas the $\mathrm{AUC}_{0-t}$ value of the parent drug was only 1.5-fold higher (Zhong et al., 2014). M7 is a sensitive substrate of two renal transporters, namely, OAT1 and OAT3; M8-1 and M8-2 are the only substrates of OAT3 (Zhong et al., 2014). Therefore, it has been speculated that the significant elevation in the plasma exposures of conjugated metabolites may be mediated by the altered expression or activities of OAT1 and OAT3 in the kidneys of patients with renal impairment. In terms of uptake clearance $\left(V_{\max } / K_{m}\right.$, where $V_{\max }$ is the maximum uptake rate, and $K_{m}$ is the Michaelis-Menten constant), OAT1 (17.0 $\mu \mathrm{l} / \mathrm{min} / \mathrm{mg}$ protein) and OAT3 (16.0 $\mu \mathrm{l} / \mathrm{min} / \mathrm{mg}$ protein) present similar contributions to the renal uptake of M7 (Zhong et al., 2014). Additionally, the $V_{\max } / K_{m}$ of M7 by OAT3 is higher than that of M8-1 (1.0 $\mu \mathrm{l} / \mathrm{min} / \mathrm{mg}$ protein) and M8-2 (1.7 $\mu \mathrm{l} / \mathrm{min} / \mathrm{mg}$ protein), indicating that M7 is a more sensitive substrate for OAT3 than glucuronide conjugates (Zhong et al., 2014). If the increase in the plasma exposure is only mediated by the altered expression of transporters, the change of M7 caused by OAT1 and OAT3 should be significantly higher than that of M8-1 or M8-2 caused only by OAT3. However, the concentration increase of three conjugates is similar. Hence, we hypothesized that some other mechanisms accounted for the boosted plasma exposures of morinidazole-conjugated metabolites in severe renal failure patients; for instance, accumulated uremic toxins may affect the renal uptake of the conjugates.

The $5 / 6$ nephrectomized $(5 / 6 \mathrm{Nx})$ rat model is characterized by hyperfiltration in the remaining nephrons (Anderson et al., 1985), which is employed to mimic CRF in humans. Naud et al. (2011) showed a decrease in protein $(40 \%)$ and mRNA (75\%) expression for Oat 1 as well as reduced protein $(87 \%)$ and mRNA $(70 \%)$ expression for Oat 3 in the kidneys of rats 41 days after 5/6 nephrectomy. In the 5/6 Nx rats, both uremic toxins IS and HA significantly increased (Kikuchi et al., 2010), similar to that in CRF humans. Therefore, this study used $5 / 6 \mathrm{Nx}$ rats for in vivo and in vitro experiments, such as kidney slices. In addition, OAT1 or OAT3 overexpressed human embryonic kidney 293 (HEK293) cells were also used to investigate the mechanism of the increased plasma exposures of morinidazole conjugates in renal failure patients.

\section{Materials and Methods}

Chemicals. Morinidazole raceme ( $99.9 \%$ purity) was kindly provided by Jiangsu Hansoh Pharmaceutical (Liangyungang, People's Republic of China). $N^{+}$-glucuronide of $S$-morinidazole M8-1 and $N^{+}$-glucuronide of $R$-morinidazole M8-2 were isolated and purified from human urine as previously described elsewhere (Gao et al., 2012). Sulfate conjugate of morinidazole M7 was synthesized as previously described elsewhere with minor modifications (Shrestha et al., 2011). HA and IAA were purchased from J\&K Scientific

TABLE 1

Biochemical parameters of control and 5/6 Nx rats

Data are expressed as mean \pm S.D.

\begin{tabular}{lcc}
\hline \multicolumn{1}{c}{ Parameter } & $\begin{array}{c}\text { Control Rats } \\
(n=19)\end{array}$ & $\begin{array}{c}5 / 6 \mathrm{Nx} \text { Rats } \\
(n=34)\end{array}$ \\
\hline Body weight $(\mathrm{g})$ & $379 \pm 32$ & $313 \pm 32^{a}$ \\
Serum BUN $(\mathrm{mM})$ & $6.91 \pm 8.14$ & $49.0 \pm 23.7^{a}$ \\
Serum creatinine $(\mu \mathrm{M})$ & $40.6 \pm 34.2$ & $117 \pm 62^{b}$ \\
Urinary protein excretion (mg/day) & $16.1 \pm 3.5$ & $54.7 \pm 54.9^{c}$ \\
Creatinine CL (ml/kg body weight/min) & $16.8 \pm 17.7$ & $4.45 \pm 3.55^{c}$ \\
\hline
\end{tabular}

\footnotetext{
CL, clearance.

${ }^{a} P<0.001$ compared with control.

${ }^{b} P<0.01$ compared with control.

${ }^{c} P<0.05$ compared with control.
} 
A

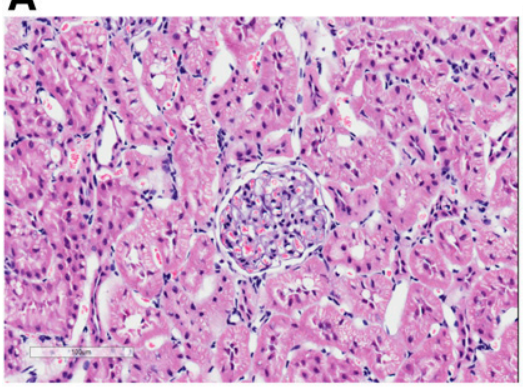

C

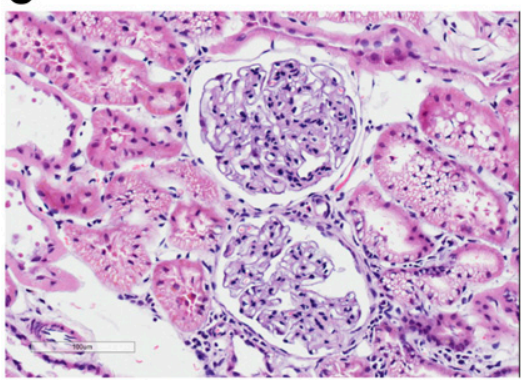

B

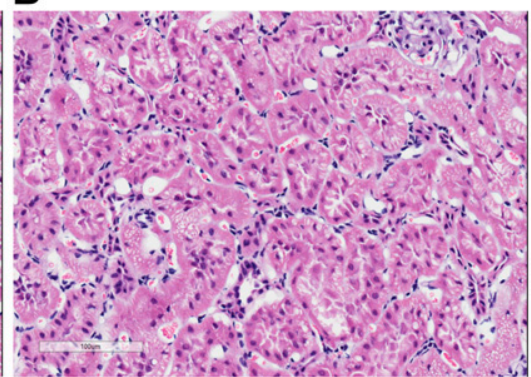

D

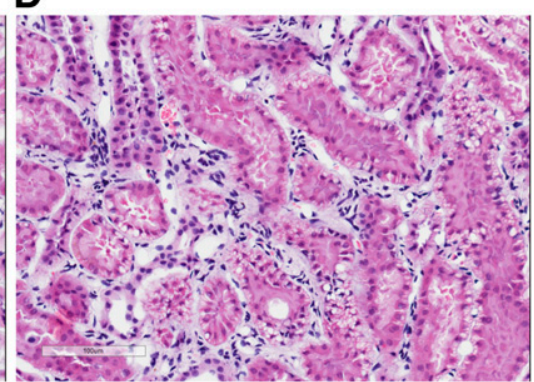

Fig. 2. Histologic sections of renal glomerulus from control rat (A) and 5/6 Nx rat (C), and renal tubules from control rat (B) and 5/6 $\mathrm{Nx}$ rat (D).
(Beijing, People's Republic of China). Salicylic acid was purchased from Meilun Biology Technology (Dalian, People's Republic of China). Indoxyl sulfate potassium salt, sodium pentobarbital, metronidazole, probenecid, Hanks' balanced salt solution (HBSS), and hygromycin B were obtained from SigmaAldrich (St. Louis, MO). CMPF was obtained from Toronto Research Chemicals (North York, ON, Canada). The BCA protein assay kit was purchased from Beyotime (Jiangsu, People's Republic of China). Assay kits of creatinine, urine protein, and blood urea nitrogen (BUN) were supplied by Nanjing Jiancheng
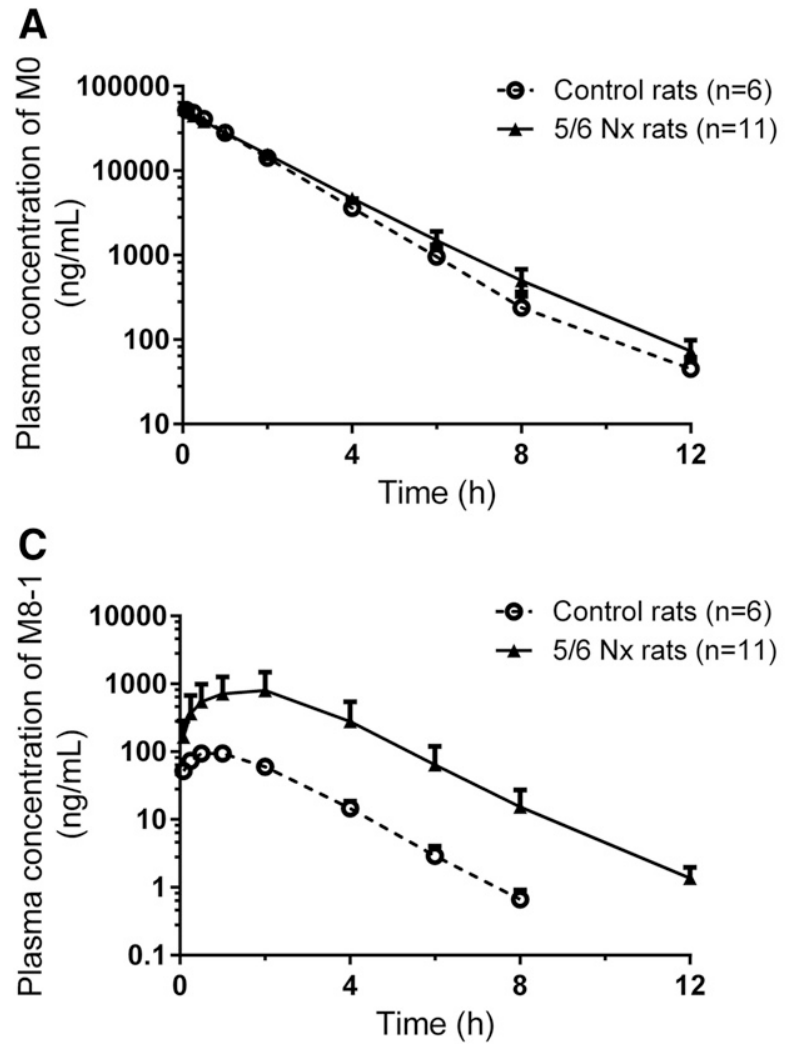

Bioengineering Institute (Jiangsu, People's Republic of China). TRIzol regent, diethyl pyrocarbonate-treated water, Dulbecco's modified Eagle's medium, fetal bovine serum, $0.05 \%$ trypsin-EDTA, penicillin G, streptomycin, and SuperScript III reverse transcriptase kit were purchased from Invitrogen (Carlsbad, CA). Deionized water was obtained using a Millipore Milli-Q gradient water purification system (Molsheim, France). All other solvents and regents were of either high-performance liquid chromatography or analytic grade.

B
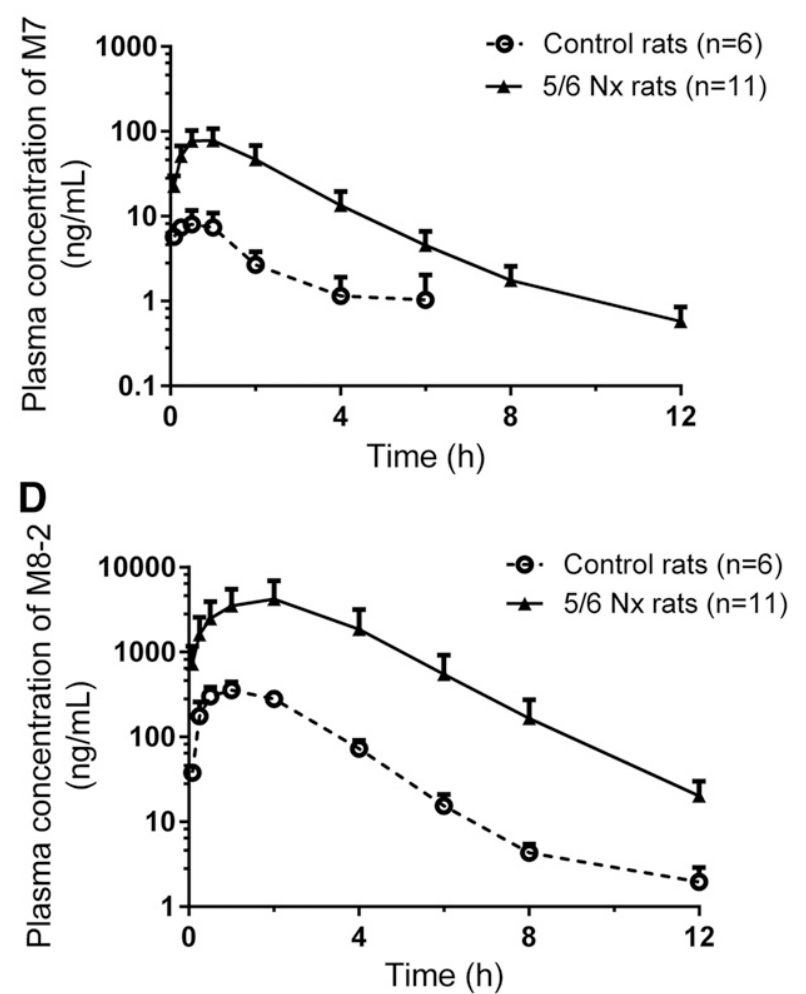

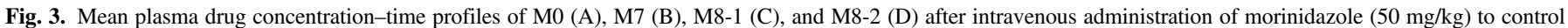
and $5 / 6 \mathrm{Nx}$ rats. 
TABLE 2

Pharmacokinetic parameters of morinidazole and its major metabolites after an intravenous administration of $50 \mathrm{mg} / \mathrm{kg}$ of morinidazole to control $(\mathrm{n}=6)$ and $5 / 6 \mathrm{Nx}(\mathrm{n}=11)$ rats

Data are expressed as mean \pm S.D.

\begin{tabular}{|c|c|c|c|c|}
\hline \multirow{2}{*}{ Pharmacokinetic Parameters } & \multirow{2}{*}{$\frac{\text { Morinidazole }}{\text { M0 }}$} & \multirow{2}{*}{$\begin{array}{c}\text { Sulfate Conjugate } \\
\text { M7 }\end{array}$} & \multicolumn{2}{|c|}{ Glucuronide Conjugates } \\
\hline & & & M8-1 & M8-2 \\
\hline \multicolumn{5}{|l|}{ Control rats } \\
\hline$C_{\max }(\mu \mathrm{g} / \mathrm{ml})$ & $48.2 \pm 6.1$ & $0.00928 \pm 0.00337$ & $0.0988 \pm 0.0134$ & $0.356 \pm 0.087$ \\
\hline$t_{\max }(\mathrm{h})$ & $0.08 \pm 0.00$ & $0.46 \pm 0.29$ & $0.75 \pm 0.27$ & $1.00 \pm 0.00$ \\
\hline$t_{1 / 2}(\mathrm{~h})$ & $1.16 \pm 0.09$ & $1.24 \pm 0.34$ & $0.94 \pm 0.11$ & $1.49 \pm 0.28$ \\
\hline $\mathrm{AUC}_{0-t}(\mu \mathrm{g} \cdot \mathrm{h} / \mathrm{ml})$ & $87.2 \pm 11.7$ & $0.0164 \pm 0.0076$ & $0.257 \pm 0.037$ & $1.12 \pm 0.36$ \\
\hline $\operatorname{AUC}_{0-\infty}(\mu \mathrm{g} \cdot \mathrm{h} / \mathrm{ml})$ & $87.3 \pm 11.7$ & $0.0177 \pm 0.0081$ & $0.257 \pm 0.037$ & $1.12 \pm 0.36$ \\
\hline $\mathrm{CL}(\mathrm{ml} / \mathrm{h} / \mathrm{kg})$ & $582 \pm 77$ & & & \\
\hline$V_{\mathrm{ss}}(\mathrm{ml} / \mathrm{kg})$ & $805 \pm 71$ & & & \\
\hline MRT (h) & $1.39 \pm 0.12$ & $1.75 \pm 0.33$ & $1.86 \pm 0.22$ & $2.21 \pm 0.38$ \\
\hline \multicolumn{5}{|l|}{$5 / 6 \mathrm{Nx}$ rats } \\
\hline$C_{\max }(\mu \mathrm{g} / \mathrm{ml})$ & $53.2 \pm 3.5^{a}$ & $0.0828 \pm 0.0293^{b}$ & $0.810 \pm 0.680^{a}$ & $4.25 \pm 2.68^{c}$ \\
\hline$t_{\max }(\mathrm{h})$ & $0.08 \pm 0.00$ & $0.82 \pm 0.25^{a}$ & $1.64 \pm 0.50^{b}$ & $1.91 \pm 0.30^{b}$ \\
\hline$t_{1 / 2}(\mathrm{~h})$ & $1.32 \pm 0.08^{c}$ & $1.88 \pm 0.79$ & $1.06 \pm 0.08^{a}$ & $1.28 \pm 0.11$ \\
\hline $\mathrm{AUC}_{0-t}(\mu \mathrm{g} \cdot \mathrm{h} / \mathrm{ml})$ & $91.2 \pm 8.7$ & $0.211 \pm 0.081^{b}$ & $2.76 \pm 2.36^{a}$ & $15.7 \pm 10.0^{c}$ \\
\hline $\operatorname{AUC}_{0-\infty}(\mu \mathrm{g} \cdot \mathrm{h} / \mathrm{ml})$ & $91.3 \pm 8.7$ & $0.214 \pm 0.081^{b}$ & $2.76 \pm 2.36^{a}$ & $15.7 \pm 10.0^{c}$ \\
\hline $\mathrm{CL}(\mathrm{ml} / \mathrm{h} / \mathrm{kg})$ & $552 \pm 50$ & & & \\
\hline$V_{\mathrm{ss}}(\mathrm{ml} / \mathrm{kg})$ & $891 \pm 41^{c}$ & & & \\
\hline MRT (h) & $1.62 \pm 0.12^{c}$ & $2.13 \pm 0.13^{a}$ & $2.30 \pm 0.19^{c}$ & $2.65 \pm 0.22^{c}$ \\
\hline
\end{tabular}

$\mathrm{AUC}_{0-\infty}$, area under the concentration-time curve from 0 hour to the infinite time; CL, total body clearance; $C_{\max }$, maximum plasma concentration; $t_{\max }$, time to the $C_{\max } . t_{1 / 2}$, apparent elimination half-life; MRT, mean residence time; $V_{\mathrm{SS}}$, volume of distribution at steady state.

${ }^{a} P<0.05$ compared with control.

${ }^{b} P<0.001$ compared with control.

${ }^{c} P<0.01$ compared with control.

Construction of 5/6 Nx rat model. All procedures involving animals were performed in accordance with Guide for the Care and Use of Laboratory Animals of the Shanghai Institute of Materia Medica, Chinese Academy of Sciences. Male Sprague-Dawley (SD) rats weighing $180 \mathrm{~g}$ to $220 \mathrm{~g}$ were allowed an acclimatization period of at least 7 days before the first nephrectomy. CRF was induced by two-stage 5/6 nephrectomy, as previously described elsewhere (Deguchi et al., 2003). After anesthesia with sodium pentobarbital $(50 \mathrm{mg} / \mathrm{kg}$ ) by intraperitoneal injection, the left kidney was exposed to excise the upper and lower poles of about one-third, respectively. After 7 days, the rats were anesthetized again, and the whole right kidney was removed. Control rats were subjected to sham operations identical to those used for $5 / 6 \mathrm{Nx}$ rats except that the kidneys or renal poles were not removed. All rats were allowed free access to water, and the control rats were fed the same amount of fodder that $5 / 6$ $\mathrm{Nx}$ rats consumed on the previous day to reduce the imbalance on the weights (Naud et al., 2011).

On the day 41 after nephrectomy, urine was collected for 24 hours to determine the clearance of creatinine and urine protein. Blood samples were allowed to stand for 30 minutes and then centrifuged at $11,000 \mathrm{rpm}$ for 5 minutes to obtain serum samples for measurement of serum creatinine and BUN.

Pharmacokinetic Experiments. Animals were fasted for 12 hours with free access to water before the experiments. Morinidazole was administered intravenously via the tail to $5 / 6 \mathrm{Nx}$ rats $(n=11)$ and control rats $(n=6)$ at a dose of $50 \mathrm{mg} / \mathrm{kg}$. Blood samples were collected from retro-orbital venous plexus before the dose ( 0 hours), at 5, 15, and 30 minutes, and at 1, 2, 4, 6, 8, and 12 hours after the dose in tubes containing an anticoagulant. Plasma samples were centrifuged at $11,000 \mathrm{rpm}$ for 5 minutes at $4^{\circ} \mathrm{C}$ and then stored at $-20^{\circ} \mathrm{C}$ until analysis.

After the pharmacokinetic experiments, the rats were anesthetized immediately for excision of the remnant kidneys of 5/6 Nx rats and the left kidneys of control rats. Each kidney was divided into two parts: one part was fixed in $4 \%$ formalin for $\mathrm{H} \& \mathrm{E}$ stain, and the other part was frozen immediately in liquid nitrogen and then stored at $-80^{\circ} \mathrm{C}$.

To investigate the pharmacokinetics of $\mathrm{M} 7,5 / 6 \mathrm{Nx}$ rats $(n=13)$ and control rats $(n=9)$ were intravenously injected into the tail vein at a dose of $15 \mathrm{mg} / \mathrm{kg}$. Blood samples were collected before the dose ( 0 hours), at 5, 15, 30 , and 45 minutes, and at $1,1.5$, and 2 hours after the dose. Plasma samples were harvested, and tissue samples were processed the same as previously described.
Before the pharmacokinetic experiment of $\mathrm{M} 7$ in $5 / 6 \mathrm{Nx}$ rats, the dose dependency of M7 pharmacokinetic parameters was examined in normal SD rats. Twelve normal SD rats were randomly divided into three groups. M7 was administrated intravenously via the tail vein with different doses: $0.1,1.5$, and $15 \mathrm{mg} / \mathrm{kg}$. Blood samples were collected at 5, 15, 30, and 45 minutes, and at 1, 1.5, and 2 hours after dose administration. Plasma samples were harvested as previously described.

Tissue Distribution. Normal SD rats $(n=24)$ weighing $180 \mathrm{~g}$ to $220 \mathrm{~g}$ were randomly divided into two groups, which were fasted for 12 hours with free access to water before the experiments. Morinidazole was administered intravenously via tails of 12 rats at a dose of $50 \mathrm{mg} / \mathrm{kg}$, and M7 was administered intravenously to another 12 rats at a dose of $15 \mathrm{mg} / \mathrm{kg}$. At $0.25,0.75$, and 1.50 hours after dose administration, rats ( $n=4$ at each time point in each group) were sacrificed via exsanguination from the abdominal aorta under anesthesia. Livers, kidneys, lungs, hearts, and spleens were rapidly dissected, washed with saline, dried, and weighed. Every $200 \mathrm{mg}$ of the tissue samples was homogenized with $1 \mathrm{ml}$ of saline and stored at $-20^{\circ} \mathrm{C}$ until analysis. Blood samples were collected and centrifuged to harvest plasma samples. All plasma samples were stored at $-20^{\circ} \mathrm{C}$.

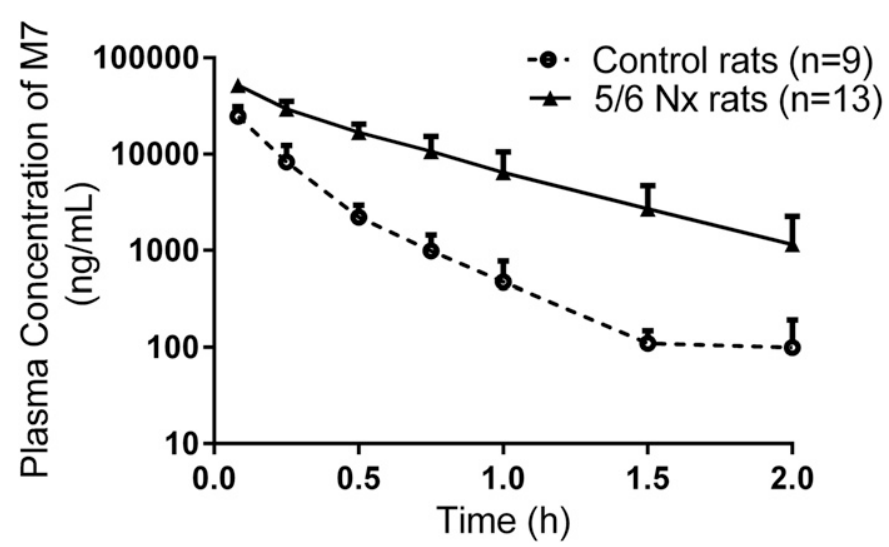

Fig. 4. Mean plasma drug concentration-time profiles of $M 7$ after intravenous administration of M7 (15 mg/kg) to control and 5/6 Nx rats. 
Biochemistry and Histopathologic Examination. Urine creatinine and protein, serum creatinine, and BUN were determined using the corresponding assay kits in accordance with the manufacturer's instruction. Formalin-fixed tissues were embedded in paraffin, cut into slices, and stained with H\&E. H\&E sections were observed with optical microscopy.

mRNA Analysis. RNAs of renal cortex were extracted using TRIzol regent. We synthesized cDNA from $1 \mu \mathrm{g}$ of total RNA by using a SuperScript III reverse transcriptase kit [synthesis primers were oligo (dT)]. The reaction was performed in a volume of $10 \mu \mathrm{l}$, containing $25 \mathrm{ng} / \mu \mathrm{l}$ cDNA, $250 \mathrm{nM}$ corresponding primer, and $5 \mu 1$ of QuantiFast SYBR Green Polymerase Chain Reaction (PCR) Master Mix (Qiagen, Germany) on an ABI7500 Fast Real-Time PCR system (Applied Biosystems, Foster City, CA). Quantitative PCR conditions were $95^{\circ} \mathrm{C}$ for 10 minutes, $95^{\circ} \mathrm{C}$ for 15 seconds, and $57.5^{\circ} \mathrm{C}$ for 60 seconds for 40 cycles. The sequences of primers were as follows: Oat1 (forward) $5^{\prime}$-ACCCCACAGTGATTCGGCAG-3', (reverse) 5'-GGCATGGAGGGGTAGAACTC-3'; Oat3 (forward) 5'-CAGTTTTGGTTCATCTTGCCTGGTG-3', (reverse) 5'-CCAGCAAGGTCACATGCAGGTA-3' ${ }^{\prime}$; and $\beta$-actin (forward) $5^{\prime}$-GCCACCAGTTCGCCAT- $3^{\prime}$, (reverse) 5'-CATACCCACCATCACACC-3'. The PCR products were analyzed using $\Delta \Delta \mathrm{Ct}$ (Livak and Schmittgen, 2001) with $\beta$-actin as the internal standard.

Kidney Slices. Kidney slices were experimented on as previously described elsewhere (Obatomi et al., 1998). Rats were sacrificed via exsanguination from the abdominal aorta under anesthesia, and the kidneys were excised. The kidneys were decapsulated and cored ( $8 \mathrm{~mm}$ i.d.) perpendicular to the corticopapillary axis. Kidney slices with a thickness of $300 \mu \mathrm{m}$ and a diameter of $8 \mathrm{~mm}$ were prepared in Krumdieck tissue slicer MD6000 (TSE systems, Chesterfield, MO) with ice-cold and carbogen-statured $\left(95 \% \mathrm{O}_{2}, 5 \% \mathrm{CO}_{2}\right)$ Krebs-bicarbonate buffer $\left(120 \mathrm{mM} \mathrm{NaCl}, 16.2 \mathrm{mM} \mathrm{KCl}, 10 \mathrm{mM} \mathrm{Na} 2 \mathrm{HPO}_{4} / \mathrm{NaH}_{2} \mathrm{PO}_{4}, 1.2 \mathrm{mM} \mathrm{MgSO}\right.$, and $1 \mathrm{mM} \mathrm{CaCl}_{2}, \mathrm{pH}$ 7.5) (Habu et al., 2003). After 5 minutes of preincubation at $37^{\circ} \mathrm{C}$, kidney slices were transferred to 24 well-cultured plates containing $1 \mathrm{ml}$ of buffer with test compounds for further incubation at $37^{\circ} \mathrm{C}$. All the incubations were under a carbogen atmosphere.

To study the effect of CRF on the uptake, kidney slices of 5/6 Nx rats $(n=6)$ and control rats $(n=4)$ were incubated with M7 $(30 \mu \mathrm{M})$, M8-1 $(100 \mu \mathrm{M})$, or M8$2(100 \mu \mathrm{M})$. The uptake was measured at 5 and 15 minutes. To study the effect of uremic toxins on the uptake, kidney slices of normal rats were incubated with M7 $(30 \mu \mathrm{M}), \mathrm{M} 8-1(100 \mu \mathrm{M})$, or M8-2 $(100 \mu \mathrm{M})$ in the presence or absence of probenecid and individual or mixed HA and IS with different concentrations for 15 minutes.

At the end of each incubation, kidney slices were washed 3 times with ice-cold HBSS and dried using a filter paper. After weighing, each kidney slice was homogenized with $300 \mu \mathrm{l}$ of saline. Conjugated metabolites were determined using liquid chromatography with tandem mass spectrometry (LC-MS/MS).

Cell Cultures. HEK293 cells overexpressed with human OAT1 or OAT3 and empty-vector-transfected control cells (mock) were established at HD Bioscience (Shanghai, People's Republic of China). The functions of the transporters in these cells were identified and validated using corresponding typical substrates and inhibitors. Cells were maintained in Dulbecco's modified Eagle's medium supplemented with $10 \%$ fetal bovine serum, 100 units $/ \mathrm{ml}$ of penicillin G,

\section{TABLE 3}

Pharmacokinetic parameters of M7 after an intravenous administration of $15 \mathrm{mg} / \mathrm{kg}$ M7 to control $(\mathrm{n}=9)$ and $5 / 6 \mathrm{Nx}(\mathrm{n}=13)$ rats

Data are expressed as mean \pm S.D.

\begin{tabular}{lcc}
\hline \multicolumn{1}{c}{ Parameter } & Control rats $(n=9)$ & $5 / 6 \mathrm{Nx}$ rats $(n=13)$ \\
\hline$C_{\max }(\mu \mathrm{g} / \mathrm{ml})$ & $24.7 \pm 6.4$ & $51.9 \pm 7.4^{a}$ \\
$t_{\max }(\mathrm{h})$ & $0.08 \pm 0.00$ & $0.08 \pm 0.00$ \\
$t_{1 / 2}(\mathrm{~h})$ & $0.27 \pm 0.05$ & $0.93 \pm 0.29^{a}$ \\
$\mathrm{AUC}_{0-\mathrm{t}}(\mu \mathrm{g} \cdot \mathrm{h} / \mathrm{ml})$ & $7.83 \pm 1.71$ & $28.3 \pm 6.9^{a}$ \\
$\mathrm{AUC}$ & $7.87 \pm 1.71$ & $28.5 \pm 6.9^{a}$ \\
$\mathrm{CL}(1 / \mathrm{h} / \mathrm{kg})$ & $1.98 \pm 0.41$ & $0.55 \pm 0.11^{a}$ \\
$\mathrm{~V}_{\mathrm{ss}}(1 / \mathrm{kg})$ & $0.40 \pm 0.15$ & $0.33 \pm 0.08$ \\
$\mathrm{MRT}(\mathrm{h})$ & $0.20 \pm 0.05$ & $0.61 \pm 0.17^{a}$
\end{tabular}

$\mathrm{AUC}_{0-\infty}$, area under the concentration-time curve from 0 hour to the infinite time; $\mathrm{CL}$, total body clearance; $C_{\max }$, maximum plasma concentration; $t_{\max }$, time to the $C_{\max } ; t_{1 / 2}$, apparent elimination half-life; MRT, mean residence time; $V_{\mathrm{SS}}$, volume of distribution at steady state.

${ }^{a} P<0.001$ compared with control.
$100 \mu \mathrm{g} / \mathrm{ml}$ of streptomycin, and $100 \mu \mathrm{g} / \mathrm{ml}$ of hygromycin $\mathrm{B}$ at $37^{\circ} \mathrm{C}$ in a humidified $5 \% \mathrm{CO}_{2}$ atmosphere. Cells were seeded into the wells of 24-well BD Biocoat poly-D-lysine-coated plates (BD Biosciences, Bedford, MA) at a density of $2 \times 10^{5}$ cells/well. Uptake studies were conducted 2 days after seeding, when the cells had grown to confluence.

In Vitro Inhibition Experiments of Uremic Toxins. Before the in vitro uptake study, cells were rinsed 3 times with prewarmed $\operatorname{HBSS}\left(37^{\circ} \mathrm{C}, \mathrm{pH} 7.4\right)$ and preincubated in $300 \mu \mathrm{l} \mathrm{HBSS}$ for 10 minutes at $37^{\circ} \mathrm{C}$. Equilibration HBSS was removed, and uptake experiments were initiated by the addition of $300 \mu \mathrm{l}$ HBSS containing the test compound, with or without uremic toxins. Uptake experiments were terminated at a specific time by removing the incubation buffer. Cells were then washed 3 times with ice-cold HBSS and lysed with $200 \mu \mathrm{l}$ of deionized water for multigelation. The protein content of the cell lysate was determined using the BCA protein assay kit. Cell samples were stored at $-20^{\circ} \mathrm{C}$ until analysis.

Determination of Morinidazole and Its Conjugated Metabolites. A 25- $\mu$ 1 aliquot of sample (plasma, tissue homogenate, or cell lysate) and $25 \mu \mathrm{l}$ of internal standard (50 $\mathrm{ng} / \mathrm{ml}$ of metronidazole) were mixed with $150 \mu \mathrm{l}$ of acetonitrile. After vortexing and centrifugation at $14,000 \mathrm{rpm}$ for 5 minutes, $10 \mu \mathrm{l}$ of the supernatants were diluted 10 -fold with methanol/water $(1: 1, \mathrm{vol} / \mathrm{vol})$, whereas $2 \mu \mathrm{l}$ was used for the determination of morinidazole or M7 via LC-MS/MS method (Gao et al., 2012; Zhong et al., 2014). The standard curves for morinidazole and M7 (high concentration) in plasma ranged from $10 \mathrm{ng} / \mathrm{ml}$ to $10,000 \mathrm{ng} / \mathrm{ml}$. Remnant supernatants were evaporated to dryness under a gentle stream of nitrogen at $40^{\circ} \mathrm{C}$, and residues were dissolved in $100 \mu \mathrm{l}$ of methanol/water $(1: 1, \mathrm{vol} / \mathrm{vol}), 5 \mu \mathrm{l}$ of which was used for the determination of M7, M8-1, or M8-2 via a LC-MS/MS method (Zhong et al., 2014). The standard curves ranged from $0.100 \mathrm{ng} / \mathrm{ml}$ to $300 \mathrm{ng} / \mathrm{ml}$ for M7 (low concentration), M8-1, and M8-2.

Determination of Uremic Toxins. IS, CMPF, HA, and IAA were determined using a Shimadzu LC-30AD high-performance liquid chromatography system (Kyoto, Japan) and an API6500 triple-quadrupole MS (Applied Biosystems, ON, Canada). Analyst 1.6 software (Applied Biosystems) was used for data acquisition and processing. Chromatographic separation was achieved on Venusil ASB-C18 $\left(150 \mathrm{~mm} \times 4.6 \mathrm{~mm}\right.$ i.d., $5 \mu \mathrm{m}$; Angela Technologies, Newark, DE) at $40^{\circ} \mathrm{C}$. The mobile phase was a mixture of $5 \mathrm{mM}$ ammonium acetate (A) and methanol (B) at a flow of $0.8 \mathrm{ml} / \mathrm{min}$. The gradient elution program began from $25 \% \mathrm{~B}$, increased linearly to $90 \%$ B in the next 2.7 minutes, and maintained for 1.8 minutes; in the next 1 minute, the gradient was reduced to $25 \%$ B linearly and maintained at $25 \%$ $\mathrm{B}$ until the gradient was stopped at 6 minutes.

Multiple reaction monitoring $(\mathrm{m} / \mathrm{z} 174.0 \rightarrow 129.9$ for IAA, $\mathrm{m} / \mathrm{z} .178 .0 \rightarrow 133.9$ for HA, $\mathrm{m} / \mathrm{z} 212.0 \rightarrow 131.8$ for IS, $\mathrm{m} / \mathrm{z} 239.0 \rightarrow 194.9$ for CMPF, and $\mathrm{m} / \mathrm{z} 136.8 \rightarrow$ 92.8 for salicylic acid as internal standard) was used in the negative electrospray ionization mode with an ion spray voltage of $-4000 \mathrm{~V}$ and a source temperature of $550^{\circ} \mathrm{C}$. The nebulizer gas, heater gas, and curtain gas were set to 50,80 , and $25 \mathrm{psi}$, respectively. The standard curve ranges were 0.100 to $30 \mu \mathrm{M}$ for IAA and CMPF in plasma and 1.00 to $200 \mu \mathrm{M}$ for IS and HA.

\section{TABLE 4}

Pharmacokinetic parameters of M7 with intravenous administration of different dose in normal rats

Data are expressed as mean \pm S.D., $\mathrm{n}=4$.

\begin{tabular}{|c|c|c|c|}
\hline \multirow{2}{*}{ Parameter } & \multicolumn{3}{|c|}{ Dose } \\
\hline & 0.1 & 1.5 & 15 \\
\hline & \multicolumn{3}{|c|}{$\mathrm{mg} / \mathrm{kg}$} \\
\hline$C_{\max }(\mu \mathrm{g} / \mathrm{ml})$ & $0.0820 \pm 0.0122$ & $1.53 \pm 0.15$ & $14.1 \pm 2.7$ \\
\hline$t_{\max }(\mathrm{h})$ & $0.08 \pm 0.00$ & $0.08 \pm 0.00$ & $0.08 \pm 0.00$ \\
\hline$t_{1 / 2}(\mathrm{~h})$ & $0.26 \pm 0.05$ & $0.22 \pm 0.03$ & $0.24 \pm 0.02$ \\
\hline $\mathrm{AUC}_{0-t}(\mu \mathrm{g} \cdot \mathrm{h} / \mathrm{ml})$ & $0.0233 \pm 0.0039$ & $0.426 \pm 0.043$ & $4.09 \pm 0.72$ \\
\hline $\operatorname{AUC}_{0-\infty}(\mu \mathrm{g} \cdot \mathrm{h} / \mathrm{ml})$ & $0.0235 \pm 0.0039$ & $0.427 \pm 0.043$ & $4.10 \pm 0.72$ \\
\hline CL $(1 / \mathrm{h} / \mathrm{kg})$ & $4.36 \pm 0.76$ & $3.54 \pm 0.34$ & $3.75 \pm 0.69$ \\
\hline$V_{\mathrm{ss}}(1 / \mathrm{kg})$ & $0.63 \pm 0.09$ & $0.45 \pm 0.04$ & $0.58 \pm 0.15$ \\
\hline MRT (h) & $0.15 \pm 0.02$ & $0.13 \pm 0.01$ & $0.16 \pm 0.02$ \\
\hline
\end{tabular}

$\mathrm{AUC}_{0-\infty}$, area under the concentration-time curve from 0 hour to the infinite time; $\mathrm{CL}$, total body clearance; $C_{\max }$, maximum plasma concentration; $t_{\max }$, time to the $C_{\max } ; t_{1 / 2}$, apparent elimination half-life; MRT, mean residence time; $V_{\mathrm{SS}}$, volume of distribution at steady state. 


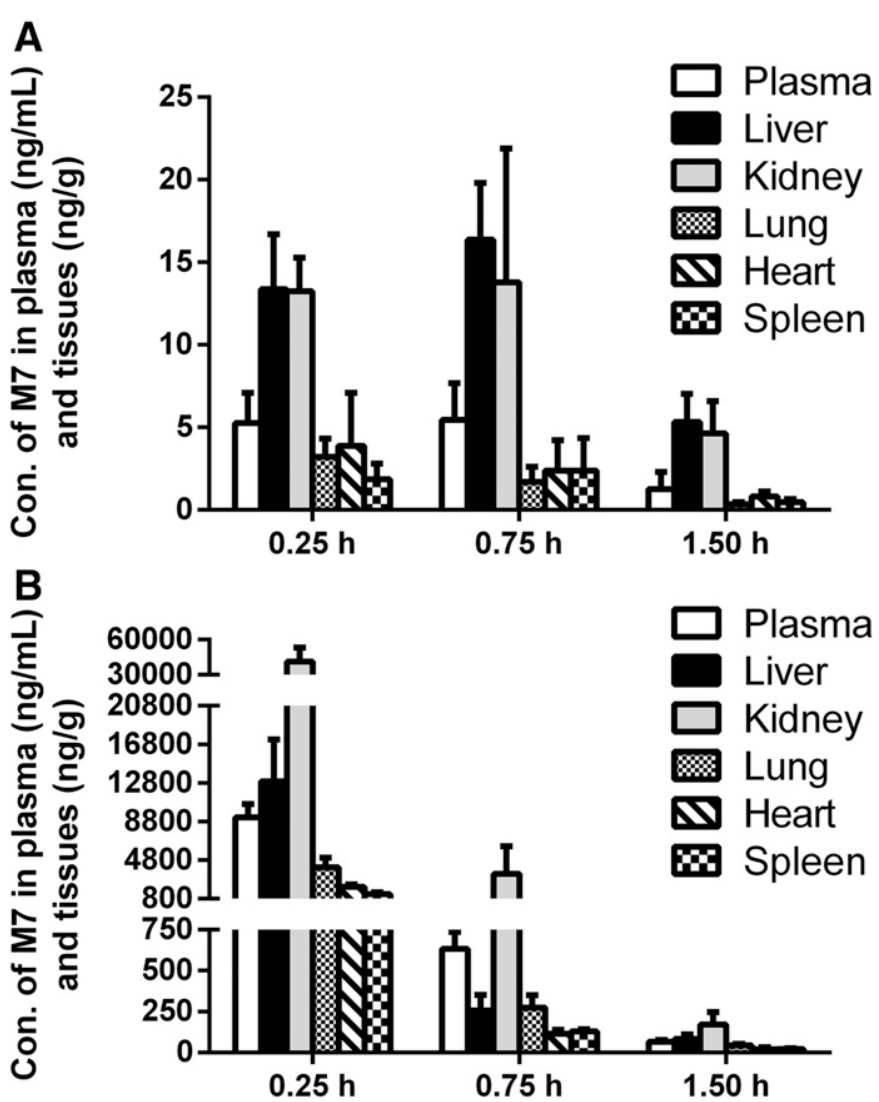

Fig. 5. Tissue distributions of M7 after intravenous administration of morinidazole (A) and M7 (B) in rats, respectively.

A $25-\mu 1$ aliquot sample (plasma or homogenate of $200 \mathrm{mg}$ of kidney $/ \mathrm{ml}$ saline) and $25 \mu \mathrm{l}$ of internal standard ( $2 \mu \mathrm{g} / \mathrm{ml}$ salicylic acid) were mixed with $75 \mu \mathrm{l}$ of acetonitrile containing $1 \%$ formic acid. After vortexing and centrifugation at 14,000 rpm for 5 minutes, supernatants were diluted 4-fold with initial mobile phase to measure IAA and CMPF and then diluted 40 times to measure HA and IS through LC-MS/MS analysis.

Data Analysis. WinNonlin (version 6.1; Pharsight Corp., Cary, NC) was used to calculate the pharmacokinetic parameters in a noncompartmental model. GraphPad Prism (version 6.0; GraphPad Software, San Diego, CA) was used to calculate the half inhibitory concentration $\left(\mathrm{IC}_{50}\right)$. All data were expressed as mean \pm standard deviation (S.D.). Student's two-tailed unpaired $t$ test in SPSS (version 20.0; SPSS Inc., Chicago, IL) was used to determine the difference. $P<$ 0.05 was considered statistically significant.

The substrate uptake rate was normalized using the protein concentration of the cell lysate. The transporter-mediated uptake was obtained by subtracting the accumulation in the HEK293 cells of mock from that in the parallel uptake experiments in OAT-transfected HEK293 cells.

In the inhibition study, $\mathrm{IC}_{50}$ values were calculated by plotting the log value of inhibitor concentration against the normalized response as follows: $Y=100 /\left[1+10^{\left(X-\operatorname{LogIC}_{50}\right)}\right]$.

\section{Results}

Biochemistry Parameters and Histopathologic Sections of Control and 5/6 Nx Rats. Table 1 presents the biochemistry parameters of control and $5 / 6 \mathrm{Nx}$ rats. Serum creatinine and BUN in $5 / 6 \mathrm{Nx}$ rats increased to 2.88 -fold $(P<0.01)$ and 7.10 -fold $(P<0.001)$ of those in control rats, respectively. By contrast, creatinine clearance in $5 / 6 \mathrm{Nx}$ rats decreased by $73.5 \%(P<0.05)$. In the H\&E-stained sections (Fig. 2), partial glomerular enlargement and increased cells in glomus were observed in 5/6 Nx rats (Fig. 2C). The tubules were dilated with tubular lumina containing proteinaceous casts, and the epithelial cells swelled in 5/6 Nx rats (Fig. 2D).

Pharmacokinetics and Tissue Distribution. Plasma concentrationtime curves of morinidazole and its conjugated metabolites after an intravenous injection of $50 \mathrm{mg} / \mathrm{kg}$ morinidazole to control and $5 / 6 \mathrm{Nx}$ rats are shown in Fig. 3. Pharmacokinetic parameters are listed in Table 2. The $\mathrm{AUC}_{0-t}$ value and plasma clearance for morinidazole were similar in both groups. However, the $\mathrm{AUC}_{0-t}$ values for morinidazoleconjugated metabolites in 5/6 Nx rats significantly increased to 12.9fold (M7), 10.7-fold (M8-1), and 14.0-fold (M8-2) of those in control rats.

Figure 4 presents the plasma concentration-time curve of sulfate conjugate M7 after direct intravenous administration of $15 \mathrm{mg} / \mathrm{kg} \mathrm{M} 7$ to control and 5/6 Nx rats; corresponding pharmacokinetic parameters are given in Table 3. The $\mathrm{AUC}_{0-t}$ value for $\mathrm{M} 7$ in $5 / 6 \mathrm{Nx}$ rats was 3.61-fold higher than that of control rats, whereas the plasma clearance for M7 decreased to $27.8 \%$ in $5 / 6 \mathrm{Nx}$ rats.

The dose dependency of M7 pharmacokinetic parameters was examined in normal SD rats (Table 4). The increased $\mathrm{AUC}_{0-t}$ values of M7 were proportional to the doses from $0.15 \mathrm{mg} / \mathrm{kg}$ to $15 \mathrm{mg} / \mathrm{kg}$,
A
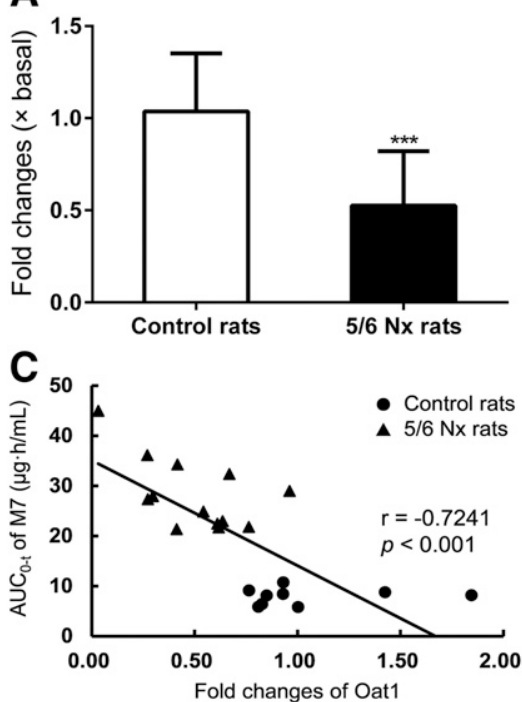

B
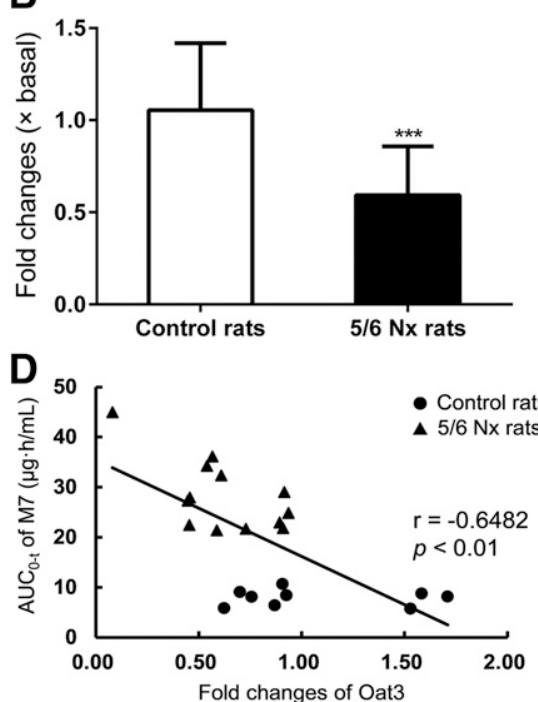

Fig. 6. mRNA expression of renal transporter Oat1 (A) and Oat3 (B) in control $(n=9)$ and 5/6 Nx $(n=13)$ rats. Correlation between the $\mathrm{AUC}_{0-t}$ values of $\mathrm{M} 7$ after intravenous administration of $15 \mathrm{mg} / \mathrm{kg}$ and mRNA expression of Oat1 (C) or Oat3 (D). $* * * P<0.001$ compared with control. 
indicating that renal clearance of M7 at dose of $15 \mathrm{mg} / \mathrm{kg}$ was not saturated in rats.

The tissue distributions of M7 in normal rats after intravenous administration of morinidazole or M7 are shown in Fig. 5. After direct intravenous injection of M7, the kidney was the preferred site for disposition, with the concentration 4.40-fold higher than that in the plasma at 0.25 hours after the dose. The concentration of M7 in the kidney at 1.50 hours after the dose was less than $1 \%$ of that at 0.25 hours, indicating a low tissue retention (Fig. 5B). After the intravenous injection of morinidazole, the relatively high concentrations of M7 were observed in the liver and kidney and lasted a relatively long period of time (Fig. 5A), probably because M7 was formed through the sulfation of the parent drug in these tissues.

mRNA Expression of Oat1 and Oat3 in Control and 5/6 Nx Rat Kidneys. Figure 6 presents the mRNA expression of Oat 1 and Oat 3 in control and 5/6 Nx rats. There were significant decreases in the mRNA expression of Oat1 $(49.3 \%, P<0.001)$ and Oat3 $(43.8 \%, P<0.001)$ in $5 / 6 \mathrm{Nx}$ rat kidneys compared with those in control rats. The relevance was investigated between mRNA expression and plasma exposure after direct intravenous administration of M7 to exclude the influence of individual differences in metabolism. Moderate correlations were observed between the $\mathrm{AUC}_{0-t}$ values of $\mathrm{M} 7$ and mRNA expression of Oat1 (coefficient $\mathrm{r}=-0.7241, P<0.001$ ) (Fig. 6C) as well as mRNA expression of Oat3 $(\mathrm{r}=-0.6482, P<0.001)$ (Fig. 6D).

Uremic Toxins in Control and 5/6 Nx Rats. In control and 5/6 Nx rats, only three of the four uremic toxins were observed, namely, IS, HA, and IAA. The plasma and kidney concentrations of IS, HA, and IAA at 2 hours after the dose were shown in Fig. 7. The concentrations of IS increased to 4.93- and 5.67-fold in the plasma and kidneys of $5 / 6 \mathrm{Nx}$ rats, whereas the concentrations of HA increased to 4.87- and 6.85-fold compared with those in control rats. The concentrations of IAA were low in both control and 5/6

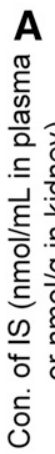

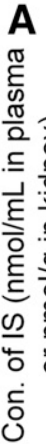

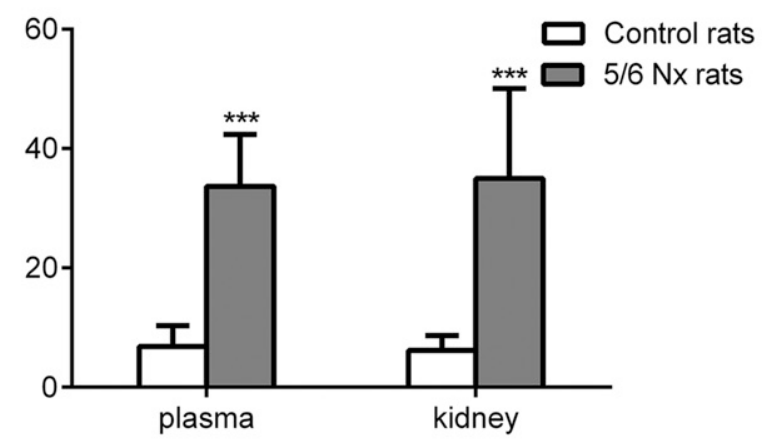

C

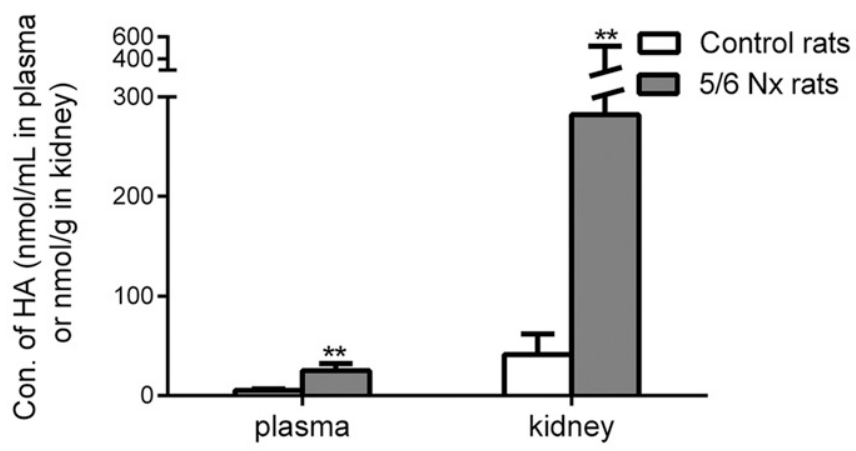

E

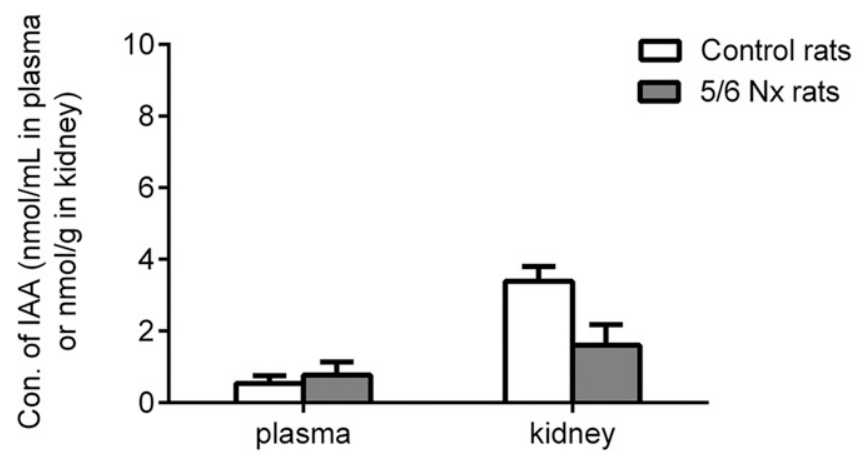

B

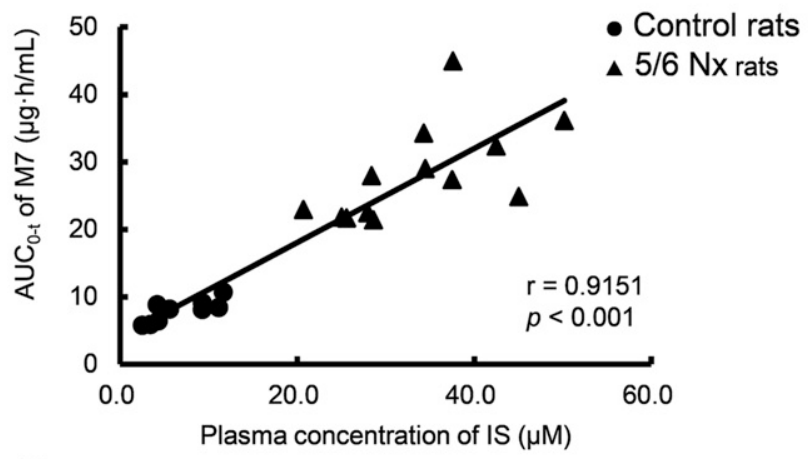

D

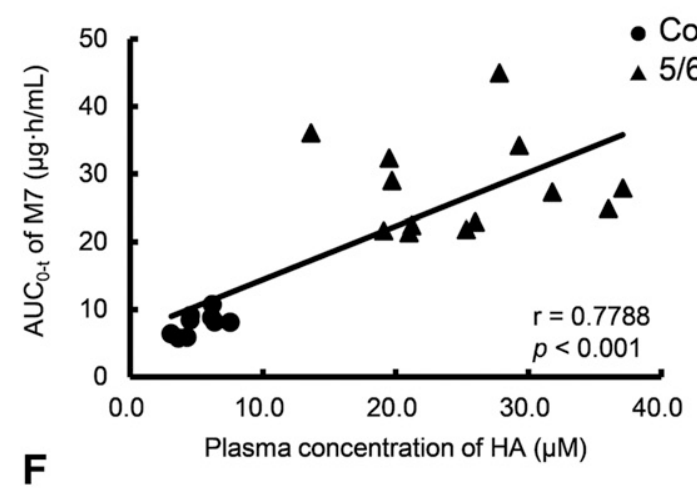

Control rats

$5 / 6 \mathrm{Nx}$ rats

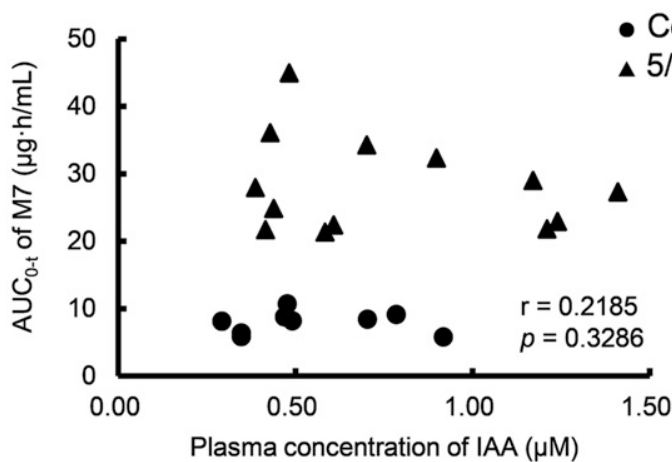

Fig. 7. Concentrations of IS (A), HA (C), and IAA (E) in plasma and kidneys of control $(n=9)$ and $5 / 6 \mathrm{Nx}(n=13)$ rats. Correlation between the AUC ${ }_{0-t}$ values of M7 $(n=22)$ and plasma concentrations of IS (B), HA (D), or IAA (F). **P< $0.01 ; * * * P<0.001$ compared with control. 
$\mathrm{Nx}$ rats but remained constant in plasma and slightly decreased in $5 / 6 \mathrm{Nx}$ rat kidneys. The relevance between uremic toxin plasma concentration and plasma exposure of M7 after direct intravenous administration was investigated to exclude the influence of individual difference in metabolism. The $\mathrm{AUC}_{0-t}$ values of $\mathrm{M} 7$ increased with the elevation of plasma concentrations of IS and HA. A correlation between the $\mathrm{AUC}_{0-t}$ values of $\mathrm{M} 7$ and plasma concentrations of IS was observed with a coefficient $r$ of $0.9151(P<0.001)$ (Fig. 7B). A correlation between the $\mathrm{AUC}_{0-t}$ values of $\mathrm{M} 7$ and plasma concentrations of HA ( $\mathrm{r}=0.7788, P<0.001$ ) (Fig. 7D) was also determined. No correlation was found between the $\mathrm{AUC}_{0-t}$ values of $\mathrm{M} 7$ and plasma concentration of IAA $(\mathrm{r}=0.2185, P=0.3286)$ (Fig. 7F).

Uptake of Morinidazole-Conjugated Metabolites in Kidney Slices. The uptakes for 5 and 15 minutes of the three conjugated metabolites, M7, M8-1, and M8-2, in the control and 5/6 Nx kidney slices are shown in Fig. 8 (A-C). Data revealed that the conjugate accumulations showed no significant difference between control and 5/6 Nx kidney slices, irrespective of incubation period.

In normal rat kidney slices, the uptakes of M7, M8-1, and M8-2 were investigated with different degrees of IS, HA, and their mixture. With the concentration of 20,100 , and $500 \mu \mathrm{M}$ IS, the uptake of M7 decreased to $91.3 \%, 63.5 \%$, and $57.3 \%$; M8-1 to $98.0 \%, 79.7 \%$, and $68.0 \%$; and M82 to $90.7 \%, 73.0 \%$, and $50.0 \%$, respectively. With the concentration of 20,100 , and $500 \mu \mathrm{M} \mathrm{HA}$, the uptake of $\mathrm{M} 7$ was decreased to $78.3 \%$, $65.0 \%$, and $38.7 \%$; M8-1 to $87.3 \%, 80.3 \%$, and $63.0 \%$; and M8-2 to $99.5 \%, 81.0 \%$, and $72.0 \%$, respectively.

The two uremic toxin mixtures of 20/20,100/100, and 500/500 $\mu \mathrm{M}$ decreased the uptake of M7 to $78.4 \%, 60.7 \%$, and $41.0 \%$; M8-1 to $73.5 \%, 46.2 \%$, and $33.3 \%$; and M8-2 to $88.2 \%, 67.3 \%$, and $57.2 \%$, respectively (Fig. 8D-F). The inhibitory effect of $200 \mu \mathrm{M}$ probenecid was also examined, which decreased the uptake of morinidazole conjugates to $54.0 \%$ (M7), 31.0\% (M8-1), and 32.0\% (M8-2), respectively.
Inhibition of Four Uremic Toxins for the Uptake of Morinidazole-Conjugated Metabolites in OAT1/OAT3 Overexpressed HEK293 Cells. The inhibitory effects of probenecid and different concentrations of uremic toxin mixture on the uptake of M7, M8-1, and M8-2 were evaluated (Supplemental Fig. 1). The inhibitory effect of individual uremic toxin, CMPF, HA, IS, and IAA was independently investigated. The four uremic toxins inhibited OAT1-mediated uptake of M7 and OAT3-mediated uptakes of three conjugated metabolites in a concentration-dependent manner (Fig. 9); the $\mathrm{IC}_{50}$ values are listed in Table 5.

\section{Discussion}

In severe renal failure patients, plasma exposures of the conjugated metabolites of morinidazole, M7, M8-1, and M8-2 significantly increased by over 15-fold compared with healthy subjects, whereas the plasma exposure of morinidazole increased by only $50 \%$ (Zhong et al., 2014). In this study, similar changes were found in $5 / 6$ nephrectomized rats (Fig. 3 and Table 2); hence, they were used to mimic the in vivo CRF condition for further investigation of the relationship between pharmacokinetic alterations and transporters. Biochemistry parameters and histopathologic sections showed that the CRF model was successfully constructed.

Sulfate conjugate M7 was synthesized to directly evaluate the pharmacokinetics in 5/6 $\mathrm{Nx}$ and control rats, excluding the influence of the metabolism from morinidazole to $\mathrm{M} 7 . \mathrm{N}^{+}$-glucuronide conjugates were difficult to synthesize, so the pharmacokinetics of M8-1 and M8-2 were not directly assessed. Compared with control rats, the plasma clearance of $\mathrm{M} 7$ in 5/6 Nx rats significantly decreased to $27.8 \%$, whereas the MRT and $\mathrm{AUC}_{0-t}$ values increased by 3.05 -fold and 3.61-fold, respectively (Table 3 ). These data further indicated that renal impairment in the 5/6 nephrectomized rats caused decelerated elimination of M7. Therefore, the plasma exposure was increased. Considering that the area under the plasma concentration-time curve (AUC) value of M7 was
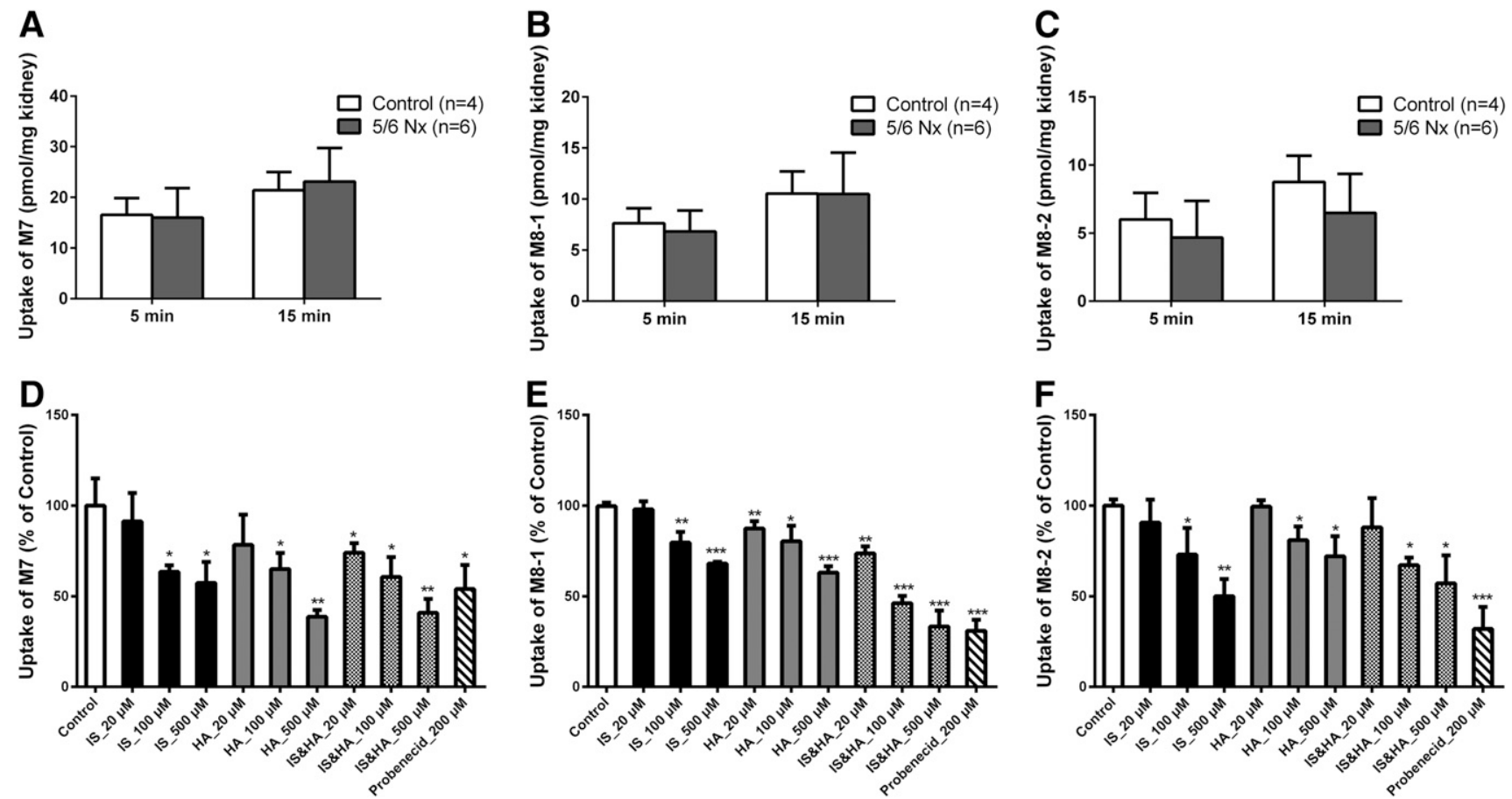

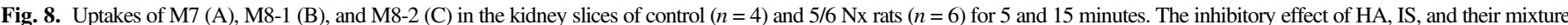

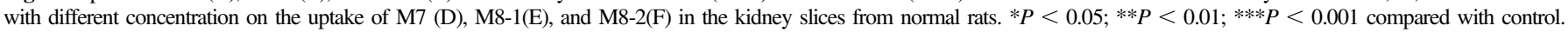



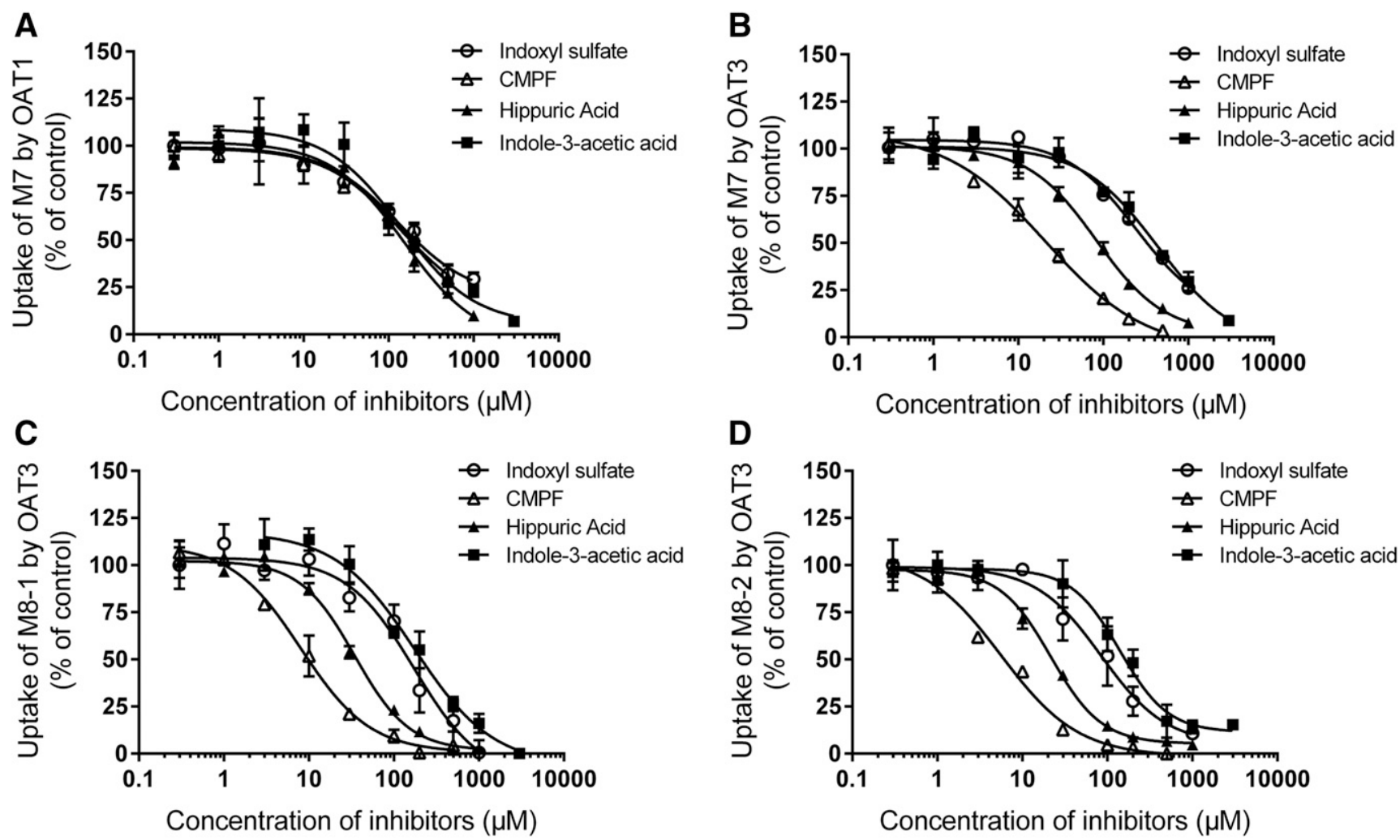

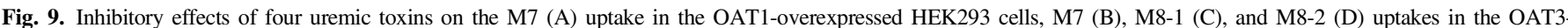

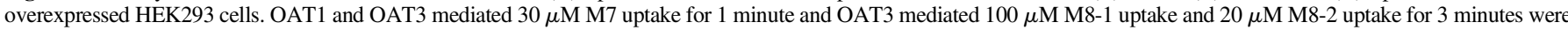

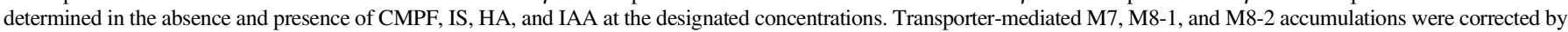

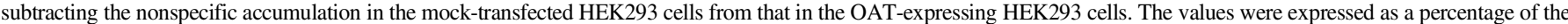
uptake in the absence of uremic toxins. Solid lines represent the fitted line obtained by nonlinear regression analysis. Each point was presented as mean \pm S.D. $(n=3)$.

elevated but morinidazole was not, the changes of transporters related to M7 were investigated.

In 5/6 Nx rats, mRNA expression of Oat1 and Oat3 decreased to approximately 50\% (Fig. 6, A and B). To further confirm whether the decreased mRNA levels of transporters induced the changes in the uptakes of the conjugated metabolites, we conducted experiments on fresh kidney slices from $5 / 6 \mathrm{Nx}$ and control rats. Accumulations of the three conjugated metabolites increased over time but showed no significant difference between control and 5/6 Nx kidney slices (Fig. 8, A-C). Although the mRNA expression decreased, the activities of two transporters presented no apparent effect on the uptakes of the conjugated metabolites. As a result, the down-regulated expression of transporters may not induce the increase in the plasma exposures of morinidazole-conjugated metabolites.

Recent studies have shown that protein-bound uremic toxins increased abnormally in the plasma of CRF patients (Vanholder et al., 2003; Fujita et al., 2011; Itoh et al., 2012). Some of these uremic toxins were proved to be substrates of renal transporters, OAT1 or OAT3 (Deguchi et al., 2004). In the present study, IS, HA, and IAA could be determined in 5/6 Nx rats. Correlation was found between the AUC values of M7 and plasma concentrations of IS or HA, but no correlation was observed between the AUC and the plasma concentration of IAA (Fig. 7). Therefore, IS, HA, and their mixture were used to evaluate their effects on the renal uptakes of M7, M8-1, and M8-2. As shown in Fig. 8 (D-F), individual and mixtures of IS and HA dose-dependently inhibited the uptakes of M7, M8-1, and M8-2 in normal fresh rat kidney slices, similar to the typical Oat inhibitor probenecid (Emami Riedmaier et al., 2012).
In CRF patients, four highly elevated uremic toxins, CMPF, IS, HA, and IAA, were reported to reach $250,210,1400$, and $5 \mu \mathrm{M}$ in plasma, respectively; and the maximum concentrations were 400, 940, 2600, and $50 \mu \mathrm{M}$, correspondingly; however, the concentrations were only 30,2 , 20 , and $0.1 \mu \mathrm{M}$ in healthy humans, respectively (Vanholder et al., 2003). Thus, these uremic toxins were used to investigate the effects on the uptakes of three morinidazole-conjugated metabolites in OAT1- or OAT3-overexpressed HEK293 cells.

In OAT3-overexpressed HEK293 cells, CMPF exhibited the highest inhibitory effect with $\mathrm{IC}_{50}$ values of 19.2 (M7), 8.53 (M8-1), and $6.75 \mu \mathrm{M}$ (M8-2). These values were lower than the CMPF plasma concentration in CRF patients. The $\mathrm{IC}_{50}$ values of HA were 87.4 (M7), 39.4 (M8-1), and $24.1 \mu \mathrm{M}$ (M8-2), and the $\mathrm{IC}_{50}$ values of IS were 222 (M7), 161 (M8-1), and 78.3 $\mu \mathrm{M}$ (M8-2); these values were also lower than or similar to their plasma concentrations in

TABLE 5

$\mathrm{IC}_{50}$ values of uremic toxins on the inhibition of morinidazole conjugates uptake in OAT expressed HEK293 cells

Data are expressed as mean \pm S.D., $\mathrm{n}=3$.

\begin{tabular}{lccccc}
\hline \multirow{2}{*}{ Substrate } & Transporter & \multicolumn{4}{c}{ IC $_{50}$ values of inhibitors $(\mu \mathrm{M})$} \\
\cline { 3 - 6 } & & IS & CMPF & HA & IAA \\
\hline M7 & OAT1 & $200 \pm 42$ & $187 \pm 22$ & $162 \pm 17$ & $197 \pm 26$ \\
M7 & OAT3 & $222 \pm 28$ & $19.2 \pm 1.3$ & $87.4 \pm 6.0$ & $404 \pm 33$ \\
M8-1 & OAT3 & $161 \pm 38$ & $8.53 \pm 0.31$ & $39.4 \pm 1.8$ & $181 \pm 7$ \\
M8-2 & OAT3 & $78.3 \pm 12.7$ & $6.75 \pm 1.76$ & $24.1 \pm 2.3$ & $173 \pm 33$ \\
\hline
\end{tabular}


CRF patients. Although the plasma concentration of IAA was increased by 50 times in CRF patients, its $\mathrm{IC}_{50}$ for three conjugated metabolites was much higher than its plasma concentration in the patients, so its effect on the renal uptake and plasma exposures of the conjugates might be minor. The inhibition results indicate that the increased concentrations of CMPF, HA, and IS in CRF patients caused the inhibition of renal clearance of three conjugated metabolites, thereby boosting the plasma exposures of M7, M8-1, and M8-2.

In OAT1-overexpressed cells, the $\mathrm{IC}_{50}$ values for $\mathrm{M} 7$ were as high as 200 (IS), 187 (CMPF), 162 (HA), and $197 \mu \mathrm{M}$ (IAA). These data indicate that the inhibition of the four uremic toxins on OAT1-mediated M7 uptake was weak, although uremic toxins were reported to be inhibitors of some other substrates of OAT1 (Tsutsumi et al., 2002; Deguchi et al., 2004; Nigam et al., 2015a). This also means that CMPF, HA, and IS inhibited the renal uptake of M7 mainly because of their inhibitory effects on OAT3 but not OAT1. This could explain the similar elevated folds of AUC values between M7 and M8-1 or M8-2 in renal impairment patients, although M7 was the substrate of OAT1 and OAT3 and M8-1 or M8-2 was substrate of only OAT3. The inhibitory mechanism of uremic toxins needs further research. Recent metabolomic data from Oat3-knockout mice and in vitro studies support the viewpoint that OAT3 is a major elimination route for many phase 2 metabolites, such as the glucuronides (Wu et al., 2013; Nigam et al., 2015b). The inhibitory effect of the uremic toxins on OAT could lead to potential disposition alterations of drugs and conjugated metabolites in kidney disease.

The AUC value of M7 increased by 12.9 -fold in 5/6 Nx rats after an intravenous injection of morinidazole. By contrast, the AUC value of M7 increased by only 3.61-fold in 5/6 Nx rats after a direct intravenous injection of M7. After M7 is directly administered to rats, their kidney concentrations were much higher $(>1000$-fold) than those in rats receiving morinidazole. Therefore, it was inferred that the kidney uptakes of M7 may be saturated or inhibited at higher M7 concentrations, which can explain different increase trends of M7 plasma exposure in $5 / 6 \mathrm{Nx}$ rats after intravenous injection of M7 and morinidazole, respectively.

Conjugated metabolism was not only a major elimination route of xenobiotics, some conjugated metabolites also exerted pharmacologic or adverse effects. For instance, glucuronide conjugate of gemfibrozil was a stronger inhibitor of CYP2C8 than the parent drug, which might cause rhabdomyolysis (Ogilvie et al., 2006); morphine- $6 \beta$-glucuronide was a more potent opioid agonist than morphine (Frances et al., 1992); and the sulfate of minoxidil demonstrated hypotensive effect similar to the parent drug (Meisheri et al., 1988). Therefore, the mechanisms of the changes in pharmacokinetics of the conjugated metabolites should be considered.

Increased evidence has reported that the alteration of endogenous substances in disease conditions might not only cause related syndromes, but may have indirect (down-regulation) and direct effects on transporters and metabolic enzymes. For instance, one of the bile acids, taurolithocholic acid, which might increase in hepatic and intestinal diseases, exhibits strong inhibitory effects on UDPglucuronosyltransferases and subsequently induces possible metabolic disorders (Fang et al., 2013). Clarification of the influential mechanism might provide some basis for therapeutic managements. Our study suggests that in CRF patients decreasing uremic toxin levels might help to reverse the altered pharmacokinetics of morinidazole-conjugated metabolites.

In conclusion, although the mRNA expression levels of Oat 1 and Oat 3 decreased in 5/6 Nx rats, their activities were not significantly affected. Accumulations of CMPF (only detected in humans), HA, and IS, which were caused by renal impairment in humans and rats, inhibited the OAT3-mediated uptake of sulfate or $N^{+}$-glucuronides in the kidney, leading to deceleration of renal excretion and consequent elevation in plasma exposure. Therefore, in disease conditions, we should not solely focus on the expression changes of transporters or metabolizing enzymes but should also consider the influence of altered endogenous substances on the activities of these transporters or metabolizing enzymes.

\section{Acknowledgments}

The authors thank Dr. Guoyu Pan (Shanghai Institute of Materia Medica, Chinese Academy of Sciences) for providing the Krumdieck tissue slicer6000, as well as Le Wang for help with the instrument usage.

\section{Authorship Contributions}

Participated in research design: Kong, Chen.

Conducted experiments: Kong, Pang, K. Zhong, Guo, Li.

Contributed new reagents or analytic tools: Kong, Pang, D. Zhong, Chen. Performed data analysis: Kong, Pang, Chen.

Wrote or contributed to the writing of the manuscript: Kong, Chen.

\section{References}

Anderson S, Meyer TW, Rennke HG, and Brenner BM (1985) Control of glomerular hypertension limits glomerular injury in rats with reduced renal mass. J Clin Invest 76:612-619.

Deguchi T, Kusuhara H, Takadate A, Endou H, Otagiri M, and Sugiyama Y (2004) Characterization of uremic toxin transport by organic anion transporters in the kidney. Kidney Int $\mathbf{6 5}$ : 162-174.

Deguchi T, Nakamura M, Tsutsumi Y, Suenaga A, and Otagiri M (2003) Pharmacokinetics and tissue distribution of uraemic indoxyl sulphate in rats. Biopharm Drug Dispos 24:345-355.

Emami Riedmaier A, Nies AT, Schaeffeler E, and Schwab M (2012) Organic anion transporters and their implications in pharmacotherapy. Pharmacol Rev 64:421-449.

Fang ZZ, He RR, Cao YF, Tanaka N, Jiang C, Krausz KW, Qi Y, Dong PP, Ai CZ, Sun XY, et al. (2013) A model of in vitro UDP-glucuronosyltransferase inhibition by bile acids predicts possible metabolic disorders. J Lipid Res 54:3334-3344.

Frances B, Gout R, Monsarrat B, Cros J, and Zajac JM (1992) Further evidence that morphine-6 beta-glucuronide is a more potent opioid agonist than morphine. J Pharmacol Exp Ther 262: 25-31.

Fujita K, Sunakawa Y, Miwa K, Akiyama Y, Sugiyama M, Kawara K, Ishida H, Yamashita K, Mizuno K, Saji S, et al. (2011) Delayed elimination of SN-38 in cancer patients with severe renal failure. Drug Metab Dispos 39:161-164

Gao R, Li L, Xie C, Diao X, Zhong D, and Chen X (2012) Metabolism and pharmacokinetics of morinidazole in humans: identification of diastereoisomeric morpholine $\mathrm{N}+$-glucuronides catalyzed by UDP glucuronosyltransferase 1A9. Drug Metab Dispos 40:556-567.

Habu Y, Yano I, Takeuchi A, Saito H, Okuda M, Fukatsu A, and Inui K (2003) Decreased activity of basolateral organic ion transports in hyperuricemic rat kidney: roles of organic ion transporters, rOAT1, rOAT3 and rOCT2. Biochem Pharmacol 66:1107-1114.

Itoh Y, Ezawa A, Kikuchi K, Tsuruta Y, and Niwa T (2012) Protein-bound uremic toxins in hemodialysis patients measured by liquid chromatography/tandem mass spectrometry and their effects on endothelial ROS production. Anal Bioanal Chem 403:1841-1850.

Kikuchi K, Itoh Y, Tateoka R, Ezawa A, Murakami K, and Niwa T (2010) Metabolomic analysis of uremic toxins by liquid chromatography/electrospray ionization-tandem mass spectrometry. I Chromatogr B Analyt Technol Biomed Life Sci 878:1662-1668.

Livak KJ and Schmittgen TD (2001) Analysis of relative gene expression data using real-time quantitative PCR and the $2(-\Delta \Delta \mathrm{C}(\mathrm{T}))$ method. Methods 25:402-408

Meisheri KD, Cipkus LA, and Taylor CJ (1988) Mechanism of action of minoxidil sulfate-induced vasodilation: a role for increased K+ permeability. J Pharmacol Exp Ther 245:751-760.

Moll S, Meier M, Formentini I, Pomposiello S, and Prunotto M (2014) New renal drug development to face chronic renal disease. Expert Opin Drug Discov 9:1471-1485.

Naud J, Michaud J, Beauchemin S, Hébert MJ, Roger M, Lefrancois S, Leblond FA, and Pichette V (2011) Effects of chronic renal failure on kidney drug transporters and cytochrome P450 in rats. Drug Metab Dispos 39:1363-1369.

Nigam SK (2015) What do drug transporters really do? Nat Rev Drug Discov 14:29-44.

Nigam SK, Bush KT, Martovetsky G, Ahn SY, Liu HC, Richard E, Bhatnagar V, and Wu W (2015a) The organic anion transporter (OAT) family: a systems biology perspective. Physiol Rev 95:83-123.

Nigam SK, Wu W, Bush KT, Hoenig MP, Blantz RC, and Bhatnagar V (2015b) Handling of drugs, metabolites, and uremic toxins by kidney proximal tubule drug transporters. Clin J Am Soc Nephrol 10:2039-2049.

Obatomi DK, Brant S, Anthonypillai V, Early DA, and Bach PH (1998) Optimizing preincubation conditions for precision-cut rat kidney and liver tissue slices: effect of culture media and antioxidants. Toxicol In Vitro 12:725-737.

Ogilvie BW, Zhang D, Li W, Rodrigues AD, Gipson AE, Holsapple J, Toren P, and Parkinson A (2006) Glucuronidation converts gemfibrozil to a potent, metabolism-dependent inhibitor of CYP2C8: implications for drug-drug interactions. Drug Metab Dispos 34:191-197.

Periclou A, Ventura D, Rao N, and Abramowitz W (2006) Pharmacokinetic study of memantine in healthy and renally impaired subjects. Clin Pharmacol Ther 79:134-143.

Sakurai Y, Motohashi H, Ueo H, Masuda S, Saito H, Okuda M, Mori N, Matsuura M, Doi T, Fukatsu A, et al. (2004) Expression levels of renal organic anion transporters (OATs) and their correlation with anionic drug excretion in patients with renal diseases. Pharm Res 21: 61-67. 
Sarnatskaya VV, Lindup WE, Niwa T, Ivanov AI, Yushko LA, Tjia J, Maslenny VN, Korneeva LN, and Nikolaev VG (2002) Effect of protein-bound uraemic toxins on the thermodynamic characteristics of human albumin. Biochem Pharmacol 63:1287-1296.

Schwenk MH and Pai AB (2016) Drug transporter function-implications in CKD. Adv Chronic Kidney Dis 23:76-81.

Shrestha SL, Bai X, Smith DJ, Hakk H, Casey FX, Larsen GL, and Padmanabhan G (2011) Synthesis and characterization of radiolabeled $17 \beta$-estradiol conjugates. J Labelled Comp Radiopharm 54:267-271 DOI: 10.1002/jlcr.1864.

Tsutsumi Y, Deguchi T, Takano M, Takadate A, Lindup WE, and Otagiri M (2002) Renal disposition of a furan dicarboxylic acid and other uremic toxins in the rat. $J$ Pharmacol Exp Ther 303:880-887.

Vanholder R, De Smet R, Glorieux G, Argilés A, Baurmeister U, Brunet P, Clark W, Cohen G, De Deyn PP, Deppisch R, et al.; European Uremic Toxin Work Group (EUTox) (2003) Review on uremic toxins: classification, concentration, and interindividual variability. Kidney Int $\mathbf{6 3}$ 1934-1943.

Verbeeck RK and Musuamba FT (2009) Pharmacokinetics and dosage adjustment in patients with renal dysfunction. Eur J Clin Pharmacol 65:757-773.
Wikoff WR, Nagle MA, Kouznetsova VL, Tsigelny IF, and Nigam SK (2011) Untargeted metabolomics identifies enterobiome metabolites and putative uremic toxins as substrates of organic anion transporter 1 (Oat1). J Proteome Res 10:2842-2851.

Wu W, Jamshidi N, Eraly SA, Liu HC, Bush KT, Palsson BO, and Nigam SK (2013) Multispecific drug transporter Slc22a8 (Oat3) regulates multiple metabolic and signaling pathways. Drug Metab Dispos 41:1825-1834.

Zhong K, Li X, Xie C, Zhang Y, Zhong D, and Chen X (2014) Effects of renal impairment on the pharmacokinetics of morinidazole: uptake transporter-mediated renal clearance of the conjugated metabolites. Antimicrob Agents Chemother 58:4153-4161.

Address correspondence to: Dr. Xiaoyan Chen, Shanghai Institute of Materia Medica, Chinese Academy of Sciences, 501 Haike Road, Shanghai 201203, People's Republic of China. E-mail: xychen@simm.ac.cn 